\section{Connecting approaches to code-switching in West Africa}

International Journal of Bilingualism

2014, Vol. I8(4) 447-454

(C) The Author(s) 2014

Reprints and permissions:

sagepub.co.uk/journalsPermissions.nav DOI: $10.1|77 /| 3670069|348| \mid 46$ ljb.sagepub.com

@SAGE

FRIAS/Albert-Ludwigs Universität Freiburg, Germany

Melissa Moyer

Filologia Anglesa i de Germanística, Universitat Autònoma de Barcelona, Spain

\title{
Pieter Muysken
}

Centre for Language Studies, Radboud University Nijmegen, The Netherlands; Department of Linguistics, Stellenbosch University, South Africa

This special issue of the International Journal of Bilingualism represents an important contribution to the field of code-switching (CS) not only because it is a joint collaboration between scholars based at the University of Ghana and New York University, but also because it presents new CS data sets. The contributions in this exciting volume constitute a particularly welcome addition to the still growing but already extensive body of literature on CS, for various reasons. Firstly, it brings a new group of scholars into the discursive arena. Secondly, very interesting new data sets are made available, stepping in some cases outside the mould of non-European matrix language/ European embedded language, such as the papers on Kabiye and Logba interacting with Ewe. Thirdly, a broad range of methodological approaches is presented, with techniques ranging from media studies to fine-grained phonological analysis.

The language pairs that we learn about in this volume are spoken in Togo (Kabiye-Ewe) in Ghana (Akan-English, Ewe-English, Logba-Ewe) and by Ghanaians in Italy (English-Akan). The structural and sociopragmatic accounts of these data, for the most part, confirm current explanatory models such as Myers-Scotton's (1993a, 2002) matrix language frame (MLF) model, Muysken's (2000) three-way typology of CS patterns involving alternation, congruent lexicalization and insertion, as well as Gumperz $(1982: 83)$ we-they codes and Auer's $(1984,1995)$ language negotiation sequences based on conversation-analytic exchange structures.

The present commentary reflects on sociolinguistic, pragmatic and structural/psycholinguistic issues relevant to the West African context and the specific CS data analysed in this volume. There is wide recognition in the field that the social, historical, political and economic context of language contact is crucial for understanding the way CS gets used and hence the pragmatic,

\section{Corresponding author:}

Peter Auer, Freiburg Institute for Advanced Studies Albertstr, 19 D-79104 Freiburg, Germany.

Email: peter.auer@germanistik.uni-freiburg.de 
conversational and structural shape of the data. This consensus is expressed by Bullock and Toribio (2009, p. 14), who point out that there are three major strands in the study of CS: the structural, the psycholinguistic and the sociopragmatic 'although, in principle, a full account of CS cannot be achieved without the integration of findings from each of these strands ...'. Each explanatory paradigm (sociopragmatic, structural and psycholinguistic) responds to concrete research interests and each involves quite different epistemologies about what counts as the relevant research questions, but also one must take into account different ontological considerations regarding what counts as reliable data. In the case of this commentary, we seek to bring together ideas that will help to make some of the links between sociopragmatic and structural CS in West Africa.

Given our separate areas of expertise, the three authors have decided to elaborate separate but interrelated sets of commentaries. Melissa Moyer begins with insights brought out in the papers about the sociolinguistic and sociopolitical context of CS in Ghana and Togo. Peter Auer focuses on aspects of pragmatics and conversational structure and, finally, Pieter Muysken comments more specifically on ideas regarding grammatical processing and language typology.

\section{Some sociolinguistic insights}

A sociolinguistic account of CS in West Africa must start by taking into account the sociopolitical conditions of contact between European colonizers and the various majority and minority ethnic groups that have existed historically and that have shaped language contact and the CS pairs that are discussed in the present volume. Each one of the articles gives contextual information on the situation of language contact. Dorvlo, in his contribution, provides a rich background account of language contact as relevant to speakers of Logba, an endangered language from the Na branch of Ghana-Togo Mountain (GTM) languages. (The classification of the 14 GTM languages, formerly called the Togo Remnant languages, remains unresolved. While they are definitely part of the Niger-Congo family, it is not clear whether they are part of the Kwa group of Niger-Congo. Heine (1968) divides the GTM languages into Ka and Na subgroups, with Logba a Na language.) Most speakers of Logba today are either bilingual or multilingual in Ewe, Twi (Akan) and Avatime, a neighbouring GTM language from the Ka subgroup. This linguistic diversity and ensuing multilingualism result from the geographical isolation of Logba and policies by governments and missionaries during the colonization era in the area where the GTM languages are spoken, in particular the promotion of Ewe at the expense of all other languages in this region.

Essizewa also provides substantial social and contextual information about the language contact data he analyses from Lome, the capital of Togo. Speakers of Kabiye (Gur, Niger-Congo) were displaced from northern Togo to the southern part of the country by the land 'reform' carried out by German colonizers at the beginning of the 20th century. This launched a relocation of a substantial number of Kabiye, particularly to Lome. Over the years this has continued and has intensified in the half-century since Togo gained independence. Today, of the 900,000 Kabiye speakers in Togo, it is estimated that 140,000 of them live in Lome, where Ewe is the dominant language. The resulting bilingualism in Kabiye and Ewe among the Kabiye in Lome has led to the emergence of complex modes of CS.

In contrast to the situations described by Dorvlo and Essizewa, where both of the languages in the CS dyad are Niger-Congo languages, the urban settings analysed by Flamenbaum, Guerini and Amuzu (2014) are key locations where English is used in combination with Akan (Twi) and Ewe, the two most widely spoken languages in Ghana. Ghanaian education policy is that English is to be the medium of instruction in schools from the fourth grade onwards (although often it assumes this 
role earlier, particularly in urban schools). Further, English is the language of public administration.

The multiple meanings that each language indexes for its speakers at any given point in time come from the wider historical and societal contexts. Individual speakers activate specific 'indexical orders', which, Silverstein (2003, p. 193) argues, are central to understanding how speakers 'access macro-sociological plane categories and concepts as values in the indexable realm of the micro-contextual'. The indexed micro and macro social meanings involved in CS between ethnic languages (Akan and Ewe) and English or ethnic languages are the result of different dimensions of social life, such as urban/rural origins, education, work activity and local or global orientation or stance. These account - at least in part - for local social processes of structuring the population in Ghana, as well as the meanings of Ghanaian CS practices.

Questions of language in connection with identity and power in West Africa cannot be understood without reference to the European colonial legacy in the region. Language policies are faced with two apparently opposite ideologies that Kamwangamalu (2008, pp. 171-172) identifies as ideologies of decolonization and ideologies of development. The former consists in replacing colonial languages by the languages spoken by indigenous people, while the latter assumes a need for people to continue learning and using the colonial language (particularly English) in order to participate as relevant players in the global marketplace. The tension between the two is captured by Flamenbaum's study of Twi (Akan) talk-radio debates where national identity and authenticity are expressed through Twi, but the pragmatic use of English indexes status and prestige and assigns authority to a speaker's words. The apparent contradiction between these two ideological positions entails a tension between, on one hand, the need for strengthening national identity by preserving and supporting education and language use policies in indigenous languages while, on the other hand, recognizing speakers' desire to also have access to the wider world and the global economy, which typically takes place in the colonial language English. The CS practices of bilingual speakers that are presented in this issue between indigenous languages and English can be seen as a way for Ghanaians to navigate between (re)producing local identity and at the same time having the communicative instruments to gain access to a globalized world economy. Power and prestige for West Africa today is connected to participating as an individual and as a country in both local and world economies. Language practices such as CS provide a means of valuing indigenous languages and at the same time recognizing the need for English and multilingualism to reach beyond national frontiers. Ideologies about CS as incomplete language proficiency or an imperfect way of speaking only enforce the decolonization-versus-development dichotomy. Rather, CS and the effort to promote bilingualism and multilingualism are a useful way of contesting the often oppositional ideological stances of tradition versus modernization that become associated with the exclusive adoption or use of indigenous or colonial languages, respectively.

\section{Pragmatics and conversational structure}

West Africa, as outlined in the introduction to this special issue, is a part of the world where the use of more than one language within a conversation, and often also within a sentence, is the rule, and not the exception; in particular, younger, urban, educated speakers often use the former colonial language and a regional or local language within one conversation, or even within one sentence. Because of the frequency of this 'switching', their speaking style has sometimes been described as a code of its own in the literature (see the discussion in the Introduction). Auer (1999) argues that, in such situations, CS is not the optimal term, since it is the very switching that constitutes the code. He applies the term mixing (of varieties or languages) to refer to this way of 
speaking and reserves the term CS for instances in which two codes are juxtaposed to create discourse-meaning.

Mixing is often perceived by the speakers as a variant of the matrix language. Although a large number of words in a conversation may come from the other language, the resulting way of speaking is considered a variant of the dominant language. Thus, while English provides about $30 \%$ of the words in the data set analysed by Flamenbaum in this issue, speakers and hearers generally consider the output to be Twi, the dominant language in Flamenbaum's study. Nonetheless, the mixing is noticed by participants and receives a social evaluation, which is often positive in West Africa. (For instance, the Twi/English speakers investigated by Guerini consider non-mixed talk in the ethnic languages a sign of lack of education, and of being rural.)

In the literature on bilingual talk, mixing and switching are often distinguished on the basis of their grammatical structure: when the distinction is made in this way, mixing is said to take place on the sentence level (intrasententially), while the term CS is restricted to intersentential alternations between two languages. However, it seems that this definition elevates an epiphenomenon to the level of a core criterion. Auer (1999) argues that the question of whether we are dealing with CS or mixing as a code of its own can only be answered on the level of the discourse interpretation of the juxtaposition of the two languages. Thus, if discourse-meaning is created by this juxtaposition, then the two languages are to be treated as two codes; if this is not the case, that is, if the juxtaposition has no specific ('local') meaning, it is considered part of one (mixing) code. Auer states that the first case is more likely to occur intersententially, since sentences are more suited to constitute actions, and the conversational meaning of CS is often linked to the opposition of two adjacent actions that is marked by the transition from one language to the other. However, as the paper by Flamenbaum (2014) shows, this is not always the case. In the Ghanaian examples discussed by her, discourse-related switching occurs within a sentence, for instance to set off stance markers from propositional content, or topic from comment.

Even though it is a code of its own, mixing must not be confounded with what are called 'mixed languages' in the literature on language contact ('fusion' in the terminology of Auer, 1999; cf. Auer, in 2014), a more radical step in language contact by which a new variety has emerged, and thus the mixing of two or more varieties has become a sediment (cf. Auer, 1999), creating a new monolingual variety on the basis of a bilingual input. Mixing, in contradistinction, clearly is bilingual speech.

Against this background, the two papers in this issue that deal with Twi/English bilingual talk from a pragmatic point of view (Flamenbaum, Guerini) investigate bilinguals who dominantly mix languages. Let us look at these papers a little more closely, since they raise important empirical and theoretical issues. A first empirical observation is that in West Africa (at least in Ghana), bilingual talk is very frequent, and the two languages frequently co-occur within sentences, but the notion of mixing is not trivially applicable. Rather, the juxtapositions partly have a discourse-related function. Since it is possible that CS develops into mixing over time, it is not unexpected to find data sets in which it is difficult to draw a clear line between the two. Indeed, both Flamenbaum and Guerini argue that a mixed style is emerging in Ghana (and brought along by Ghanaian immigrants to Italy).

A second empirical observation is that functional and non-functional cases of the use of two languages within one syntactic unit (sentence) often seem to be of different structural types. In Guerini's paper, the examples of mixing presented in her examples (2) and (3) clearly are of the insertional type, that is, English words and more complex 'islands' are inserted into a Twi 'matrix'; on the other hand, her example of CS (1) - as well as many more examples analysed by Guerini (2006) - are usually of the intersentential type or, if they are intrasentential, they are examples of 
Table I. Overview of the five studies in terms of the matrix/embedded distinction.

\begin{tabular}{|c|c|c|c|}
\hline Author & Matrix & Embedded & Comments \\
\hline $\begin{array}{l}\text { Rachel } \\
\text { Flamenbaum }\end{array}$ & Twi & English & $\begin{array}{l}\text { Fairly balanced; English matrix at the meta-level of } \\
\text { expectations for radio-communication in general, Twi in } \\
\text { the actual program }\end{array}$ \\
\hline $\begin{array}{l}\text { Federica } \\
\text { Guerini }\end{array}$ & Akan (Twi) & $\begin{array}{l}\text { English, } \\
\text { (Italian) }\end{array}$ & $\begin{array}{l}\text { Large number of insertions in some varieties, tendency } \\
\text { towards 'mixed variety', transported from Ghana into the } \\
\text { Italian context }\end{array}$ \\
\hline $\begin{array}{l}\text { Evershed } \\
\text { Amuzu }\end{array}$ & Ewe & English & $\begin{array}{l}\text { An Ewe-dominant structure with patterns from English } \\
\text { contributing to 'composite' CS as well }\end{array}$ \\
\hline $\begin{array}{l}\text { Komlan E. } \\
\text { Essizewa }\end{array}$ & Kabiye & Ewe & $\begin{array}{l}\text { Kabiye-dominant utterances with Ewe-inserted content } \\
\text { words or discontinuous phrases }\end{array}$ \\
\hline Kofi Dorvlo & Logba & Ewe & $\begin{array}{l}\text { Borrowing of nouns, some verbs, from Ewe and adapted } \\
\text { to Logba, some grammatical morphemes borrowed with } \\
\text { patterns }\end{array}$ \\
\hline
\end{tabular}

alternational (instead of insertional) switching. (See Muysken, 2000, for the distinction between alternational and insertional, which can be applied both to switching and mixing; cf. Auer, 1999.) It seems, then, that in this data set, mixing does not originate from switching but is an independent development (if it is a development at all). In Flamenbaum's data, a similar observation can be made. There are many cases of insertional mixing that do not seem to have a discourse-related meaning (see, for instance, manufacture in her example (1), or government, guarantee, security facility and private company in her example (6)), but the cases of discourse-related switching that provide the empirical basis of Flamenbaum's argument that switching highlights stance elements and the comment part of the utterance are of the alternational type. Provided that these observations hold true for a larger set of data, including other pairs of languages, an argument could be made for a structural basis of switching and mixing in alternational versus insertional types of bilingual talk, rather than in intrasentential versus intersentential types.

\section{Grammar and typology}

The papers in this issue as a group also provide an interesting perspective on several theoretical issues around the grammar of CS and mixing: the tenability of the MLF model (Myers-Scotton, 1993a, 1993b), the role of morphology in CS and contact, and the relation between contact and change.

Regarding the issue of the MLF model, it is clear that at one level it is useful in all five studies to adopt an asymmetrical model of CS and distinguish between a matrix and an embedded language, as shown in Table 1.

Nonetheless, the distinction is not absolute and is in some ways complex, as can be seen in the comments column of Table 1. In Flamenbaum's study, the discursive and grammatical local matrix language for the CS is Twi, but the global matrix language for the radio broadcasting is English. This leads to all kinds of tensions. Guerini argues that there are so many insertions into Akan (Twi) that a mixed code emerges. In Amuzu's study, properties of the Embedded Language English keep intruding into the Ewe-matrix CS patterns. Essizewa shows that Kabiye-Ewe bilinguals use Ewe content morphemes in everyday speech. Strikingly, Ewe lexemes, including Ewe verbs in Kabiye structures, take Kabiye morphology. Dorvlo's paper on Ewe borrowings into Logba provides a 
glimpse into the complexities of linguistic borrowing between the languages of interior Ghana, showing patterns not familiar from studies in, for example, European immigrant languages.

The other issue of concern is language change. Sometimes more complex relations between matrix and embedded languages have resulted in subtle patterns of change. This is particularly evident in Amuzu's, Essizewa's and Dorvlo's studies.

Amuzu argues that 'the distributional distinction made in monolingual Ewe between relational and non-relational possessum nominals is not being applied to English possessum nominals when they occur in CS contexts because no such distinction applies to them in monolingual English'. However, how is the information that a nominal is the possessum entity included in its lexical conceptual structure? This is sentence-level structural and semantic information, not lexical information. WIFE, for instance, can be possessed and possessor. Perhaps note that the notion of 'lexical conceptual structure' is enriched here to include the full semantic interpretation.

Whereas Ewe functions as the matrix language in Amuzu's data set, it is the intruding or embedded language in Essizewa's (and Dorvlo's) study, and to some extent the target of language shift. As Essizewa argues, it is hard to distinguish between CS and lexical borrowing. Ewe verbs are more frequently marked with Kabiye morphology than nouns (which would need to be incorporated into the Kabiye noun class system); this would suggest CS or very incipient borrowing, given the overwhelming tendency in canonical borrowing to involve nouns more often than verbs in the languages of the world (Haspelmath \& Tadmor, 2009). Essizewa cites structural reasons for the asymmetry found in his data (strongest with adjectives), but morphological adaptation is needed for verbs as much as for nouns and adjectives. Nonetheless, it is apparent from discussions elsewhere in Essisewa's work that Ewe nouns without Kabiye marking are actually quite frequent in the data.

Dorvlo's study also focuses on the integration of Ewe items, and provides some interesting contrasts with the previous study. Like Kabiye, Logba is a noun class language; Ewe, on the other hand, is not. Dorvlo shows that Ewe nouns can be and are borrowed into Logba and are integrated on the basis of semantic features into the Logba noun class system. This suggests a further stage of integration than in the case of the Kabiye/Ewe contact documented by Essizewa. Dorvlo does not comment on frequencies, but notes that Ewe verbs can be borrowed and used as locative verbs in Logba. Finally, there is evidence of integration of grammatical items such as the relativizer $x e$, as well as conjunctions and clause linkers. All this suggests indeed a difference in the degree of integration between the Kabiye/Ewe and the Logba/Ewe studies.

Thus, these studies as a whole provide new perspectives for comparative work in the area of CS in Ghana and neighbouring countries, pointing to similarities as well as differences, and providing new insights into the role of language typology and language change.

\section{Funding}

This research received no specific grant from any funding agency in the public, commercial or not-for-profit sectors.

\section{References}

Auer, P. (1984). Bilingual conversation. Amsterdam, The Netherlands, and Philadelphia, PA: John Benjamins. Auer, P. (1995). The pragmatics of code-switching: A sequential approach. In L. Milroy \& P. Muysken (Eds.), One speaker, two languages: Cross-disciplinary perspectives on code-switching (pp.115-135). Cambridge, UK: Cambridge University Press. 
Auer, P. (1999). From codeswitching via language mixing to fused lects. International Journal of Bilingualism, 3, 309-332.

Auer, P. (2014). Language mixing and language fusion: when bilingual talk becomes monolingual. In J. Besters-Dilger, C. Dermarkar, S. Pfänder \& A. Rabus (Eds.), Family effects in language contact: Modeling congruence as a factor in contact-induced change. (pp. 294-336) Berlin, Germany: Mouton de Gruyter.

Bullock, B. E., \& Toribio, A. J. (Eds). (2009). The Cambridge handbook of linguistic code-switching. Cambridge, UK: Cambridge University Press.

Guerini, F. (2006). Language alternation strategies in multilingual settings. A case study: Ghanaian immigrants in northern Italy. Bern, Switzerland: Lang.

Gumperz, J. J. (1982). Discourse strategies. Cambridge: Cambridge University Press.

Haspelmath, M., \& Tadmor, U. (2009). Loanwords in the world's languages: A comparative handbook. Berlin, Germany: Mouton de Gruyter.

Heine, B. (1968). Die Verbreitung und Gliederung der Togorestsprachen. Berlin, Germany: Dietrich Reimer. Kamwangamalu, N. M. (2008). Language policy, vernacular education and language economics in postcolonial Africa. In P. K. W. Tan \& R. Rubdy (Eds.), Language as a commodity: Global structures, local marketplaces (pp. 171-187). London, UK: Palgrave.

Muysken, P. (2000). Bilingual speech: A typology of code-switching. Cambridge, UK: Cambridge University Press.

Myers-Scotton, C. (1993a). Duelling languages: Grammatical structure in codeswitching. Oxford, UK, \& New York, NY: Oxford University Press.

Myers-Scotton, C. (1993b). Social motivations for codeswitching: Evidence from Africa. Oxford, UK: Clarendon Press.

Myers-Scotton, C. (2002). Contact linguistics: Bilingual encounters and grammatical outcomes. Oxford, UK, $\&$ New York, NY: Oxford University Press.

Silverstein, M. (2003). Indexical order and the dialectics of sociolinguistic life. Language and Communication, 23, 193-229.

\section{Author biographies}

Peter Auer received his academic training at the universities of Cologne, Manchester and Constance, where he also worked as an assistant professor of General Linguistics. From 1992 to 1998, he was professor of German linguistics at the University of Hamburg. Since 1998, he has held a chair of German linguistics at the University of Freiburg (Germany). He is presently one of the directors of the Freiburg Institute for Advanced Studies (FRIAS). He has done extensive research on the bilingualism, on phonology and dialectology, on prosody, on interaction and on spoken language from a syntactic point of view. He is the author of Bilingual Conversation (1984), Phonologie der Alltagssprache (1990), Language in Time (1999, with Elizabeth Couper-Kuhlen and Frank Müller), Sprachliche Interaktion (1999), Türkisch sprechen nicht nur die Türken: über die Unschärfebeziehung zwischen Sprache und Ethnie in Deutschland (with inci Dirim, 2004) and Aphasie im Alltag (with Angelika Bauer). He has (co-)edited 12 academic books (among them, Language and Space, 2010 [with J. E. Schmid] and Multilingualism and Multilingual Communication, 2007 [with Li Wei]) and written more than 100 articles in linguistic journals and edited volumes.

Melissa Moyer is Professor of English Linguistics at the Universitat Autònoma de Barcelona. She received degrees in Languages and Linguistics from Georgetown University, an MA in Linguistics from Stanford University, and a $\mathrm{PhD}$ from the Universitat Autònoma de Barcelona. She heads the CIEN Research team whose members are currently undertaking a funded project on mobility and multilingualism in an era of globalization. With Li Wei she edited The Blackwell Guide to Research Methods in Bilingualism and Multilingualism (2008) which won the 2009 BAAL book award. Her book Language, Migration and Social (In) equality: A Critical Sociolinguistic Perspective on Institutions and Work with A. Duchêne, and C. Roberts is forthcoming. She has published numerous book chapters and articles on language and migration and multilingualism in connection with social institutions. The most recent include Sociolinguistic Perspectives on 
Language and Multilingualism in Institutions (2012), What Multilingualism? Agency and Unintended Consequences of Multilingual Practices in a Barcelona Health Clinic. (2011), The Management of Multilingualism in Public, Private and Non-Governmental Institutions (2010).

Pieter Muysken is Academy Professor of Linguistics at Radboud University Nijmegen (Netherlands), having previously taught at Amsterdam and Leiden. He has carried out research and fieldwork in the Andes, Curacao and the Netherlands. Recent books include (2000) Bilingual Speech: A Typology of Codemixing; (2004) Adelaar with Muysken, The Languages of the Andes; (2008) Functional Categories; (2009-2011) Crevels and Muysken, Lenguas de Bolivia I-IV. His current research is concentrated in the Languages in Contact group in the Centre for Language Studies, Radboud University Nijmegen (www. ru.nl \linc), where he is studying the effect of language contact at four time scales: 5000 years in South America, 500 years in Surinam, 50 years in multilingual Netherlands and 5 years with Papiamentu- and Turkish-Dutch bilinguals, He is also collaborating with Marianne Gullberg on the interaction of linguistic and processing models for CS. 